\title{
Serviço Social e a saúde do trabalhador: uma dispersa demanda
}

\section{Social Welfare and health of the worker: a dispersed demand}

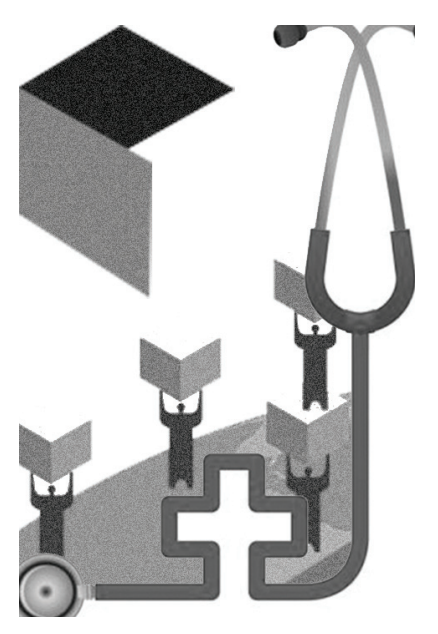

\author{
Jussara Maria Rosa Mendes* \\ Dolores Sanches Wünsch ${ }^{* *}$
}

Resumo: O presente artigo tem como objetivo discorrer sobre o Serviço Social na área da Saúde do Trabalhador, demonstrando como ao longo dos anos a profissão se aproxima dessa dispersa demanda. Apontam-se elementos que historicamente vêm norteando o debate sobre o trabalho e a saúde, expressando avanços e contradições na área da saúde do trabalhador. Para o Serviço Social, os desafios dessa área do conhecimento vêm ampliando a exigência teórica e metodológica, bem como ética e política para o enfrentamento das confrontações e manifestações contemporâneas dessas duas categorias centrais: saúde e trabalho.

Palavras-chave: Saúde do trabalhador. Serviço Social. Espaços sócio-ocupacionais

\begin{abstract}
The present article has the objective of discuss about Social Work in the field of Worker's Health, showing the way Social Work get closer to this disperse demand. Elements that historically surround the debate concerning work and health are pointed out, expressing the advances and contradictions within the field of worker's health. For Social Work, the challenges in this field of knowledge increase the theoretical and practical requirements for facing these confrontations and manifestations of these two central categories: health and work.
\end{abstract}

Keywords: Worker's health. Social Services. Social-occupational spaces.

* Assistente social, doutora em Serviço Social (PUC-SP) e professora de Serviço Social da Universidade Federal do Rio Grande do Sul (UFGRS); Coordenadora do Núcleo de Estudos e Pesquisas em Saúde e Trabalho (NEST/UFRGS) _ Porto Alegre-RS, Brasil.E-mail: jussara.mendes@ufrgs.br.

** Assistente social, doutora em Serviço Social (PUC-RS) e professora de Serviço Social da Universidade Federal do Rio Grande do Sul (UFGRS); Pesquisadora do Núcleo de Estudos e Pesquisas em Saúde e Trabalho (NEST/UFRGS) _ Porto Alegre-RS, Brasi. E-mail: doloressw@terra.com.br. 


\section{Introdução}

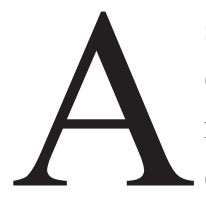

saúde do trabalhador constitui-se área do conhecimento, investigação e intervenção, que condensa um conjunto de determinações que vem reconfigurando-a ao longo das últimas décadas. Para o Serviço Social em particular, a área se constitui numa exigência ética e política frente aos impactos das transformações sociais e de forma mais precisa no que se refere às grandes proporções que ocorrem na esfera do trabalho e seus desdobramentos sobre a sociabilidade humana na atualidade. Observa-se que a área da saúde do trabalhador, historicamente, vem representando uma dispersa demanda para a profissão, em que vários fatores contribuíram para o mascaramento dessa demanda. Entre eles pode-se se apontar questões endógenas à profissão norteada pela perspectiva conservadora e outros condicionantes que limitaram a compreensão sobre o tema saúde e trabalho, bem como o pensamento hegemônico da concepção da saúde do trabalhador presente na área. Esses aspectos foram confrontados com o contexto social e político ao longo da década de 1990, e nos anos 2000 passam a se constituir em um emergente campo de atuação profissional. Tal fato significa que o assistente social é convocado e ao mesmo tempo se convoca a acolher e dar respostas às refrações do trabalho sobre a saúde do trabalhador.

A expansão da área da saúde do trabalhador pode caracterizar-se por meio de dupla dimensão: uma decorrente da nova ordem do capital sobre o trabalho; outra por conta do reconhecimento político da área, representado pela sua inserção, ainda que insuficiente, no conjunto das políticas públicas e intersetoriais, resultante da capacidade de organização de diferentes agentes políticos. No que se refere à primeira dimensão, esta assenta-se no impacto dos novos padrões de acumulação capitalista, ao se verificar, a partir do complexo da reestruturação produtiva ${ }^{1}$, uma reconfiguração do trabalho, sendo cada vez mais indissociável a análise dessas mutações sem compreender o seu impacto sobre a saúde. Na segunda dimensão, os avanços políticos-legais estão associados ao reconhecimento da concepção ampliada de saúde e sua regulação como direito universal e, ainda, à incorporação da

1. "O ‘complexo de reestruturação produtiva' envolve um sistema de inovações tecnológicas-organizacionais no campo da produção social capitalista — por exemplo, a robótica e a automação microeletrônica aplicada à produção; as novas modalidades de gestão da produção [...]. Além disso, é um importante componente do complexo de reestruturação produtiva, dos vários tipos de descentralização produtiva [...]" (Alves, 2005, p. 11). 
saúde do trabalhador no campo da saúde coletiva e em demais políticas públicas. Tais fatores conjugam-se ao crescimento da participação social na defesa e no controle social de políticas públicas, bem como ao fortalecimento da organização social dos trabalhadores e a incorporação nas pautas coletivas de necessidades voltadas para a saúde e a proteção social e do trabalho, enquanto conquista da mobilização de amplos setores da sociedade.

Esse cenário é o solo fértil da profissão, cujo objeto de intervenção comunga das expressões presentes na saúde do trabalhador e que conforma a questão social na atualidade. Ao mesmo tempo, a apropriação crítica e teórica do Serviço Social amplia as possibilidades de compreensão das manifestações que repercutem sobre o trabalho e a saúde presentes na tensão cotidiana do trabalho do assistente social frente à questão social. Em diferentes espaços sócio-ocupacionais, o Serviço Social, atento à interface saúde e trabalho, vem incorporando essa demanda, embora por vezes difusa, mas que demarcam e consolidam o seu lugar nessa área. Há de se considerar, entretanto, que a temática integra a agenda da profissão de forma incipiente. Ausente dos currículos e em grande parte do debate acadêmico, vem revelando a existência de lacunas na formação profissional em nível de graduação, muitas vezes supridas pela possibilidade da formação permanente e no âmbito da pós-graduação.

Esse conjunto de constatações dão a dimensão dos desafios para o Serviço Social na área, considerando as exigências no plano teórico e prático, representadas por meio de questões sobre o contexto societário e indagações sobre os referenciais teórico-metodológicos, que fundamentam o trabalho do assistente social e suas particularidades para o seu processamento, que é compartilhado por diferentes campos do saber. Ou seja, o Serviço Social é requisitado a responder teórica, técnica e éticamente aos impactos da confrontação cotidiana presentes nos antigos e novos contornos do processo de saúde-doença e sua relação com o trabalho.

Assim, o presente artigo tem como objetivo apresentar e discorrer sobre questões que estão sendo colocadas para o Serviço Social na área da saúde do trabalhador na atualidade. Constitui-se, inicialmente, de uma breve contextualização sobre reconhecimento da saúde do trabalhador enquanto campo teórico e político, demonstrando sua evolução conceitual e rupturas como perspectivas unilaterais e hegemônicas, além de elementos que são colocados no debate sobre o trabalho e o perfil do trabalhador. Num segundo momento, o artigo trata da dimensão teórico-metodológica na interface Serviço Social e saúde do trabalhador, buscando responder aos processos sociais que vêm impactando a saúde e o trabalho na con- 
temporaneidade. Na sequência, problematizam-se os espaços sócio-ocupacionais voltados para a área da saúde do trabalhador, os desafios para sua consolidação e as respostas da profissão. Entende-se que a abordagem proposta neste artigo sobre a temática do Serviço Social e saúde do trabalhador expressam inquietações profissionais e reflexões teóricas, as quais, acredita-se, são compartilhadas pelo conjunto de profissionais que atuam nessa área.

\section{Trabalho e a saúde do trabalhador: entre rupturas e conservadorismo}

A denominação saúde do trabalhador carrega em si as contradições engendradas na relação capital e trabalho e no reconhecimento do trabalhador como sujeito político. Ela representa o esgotamento de um modelo hegemônico que atravessou décadas, e por que não dizer séculos, circunscrito num arcabouço legal e conservador que reconhecia um risco socialmente aceitável e indenizável à lógica do capital dos acidentes de trabalho.

O surgimento da relação saúde e trabalho remonta à história social do trabalho ao longo do tempo. Essa indissociabilidade vem exigindo respostas políticas, teóricas e sociais, cuja raiz está na compreensão do trabalho, seu significado e metamorfoses. $\mathrm{O}$ trabalho, aqui entendido como processo dinâmico, representa para o trabalhador sua história individual e também coletiva. A centralidade do trabalho ${ }^{2}$ (Antunes, 1999) nas vidas das pessoas é repleta de antagonismos e contradições, pois ao mesmo tempo em que é propiciador de qualidade de vida, de satisfação das necessidades básicas, pode também representar o seu anverso, devido às condições destrutivas da organização trabalho ${ }^{3}$ na lógica do capital, que pode determinar a produção de doenças e mortes.

A construção do conhecimento e a compreensão das múltiplas determinações que constituem o processo saúde-doença incorporaram a relação dialética entre o capital e o trabalho na explicitação do conjunto de manifestações no corpo e na mente dos indivíduos. Como refere Dias,

2. A centralidade do trabalho decorre do atender a necessidade da sociabilidade através da produção dos meios de produção e de subsistência, indispensáveis à vida social. Transforma ainda o mundo natural e a própria natureza humana de maneira permanente, criando possibilidades e necessidades sociais e individuais objetivas e subjetivas (Lessa, 2007).

3. O trabalho tem uma dúplice e contraditória dimensão na medida em que possibilita criar, mas também subordinar, humanizar e degradar, libertar e escravizar, emancipar e alienar (Antunes, 2005). 
os trabalhadores vivem, adoecem e morrem de forma compartilhada com a população de um determinado tempo, lugar, e classe social, mas também, de forma diferenciada, decorrente de sua inserção particular no processo produtivo, sustenta a proposição de que esta especificidade deve ser contemplada no atendimento às suas necessidades de saúde (Dias, 1994, p. 28).

Compreender a saúde nessa dimensão significa entendê-la na divisão social e técnica do trabalho. Representa entender "o processo de trabalho como espaço concreto de exploração [...] e a saúde do trabalhador como expressão, igualmente concreta, desta exploração” (Laurell e Noriega, 1989, p. 23). Os desafios são de diferentes ordens, uma vez que o capital procura dissimular seu caráter de exploração, mas fica cada vez mais difícil esconder sua natureza, ou seja, "a nova ordem teoriza e pratica, abertamente, as desigualdades como uma necessidade intrínseca do capital" (Augusto, 2001, p. 170). Assim, fica exposta a estranha lógica na qual a igualdade tem valor negativo e a desigualdade valor positivo, a fim de naturalizar a mesma.

A configuração do trabalho no sistema capitalista tem apresentado, em seus vários ciclos, sistemas gerenciais com evolução crescente da produção, da qualificação profissional, do ritmo de trabalho e da fragmentação do processo produtivo. O contexto é de precarização, flexibilização, trabalho parcial, polivalência de funções, redução dos postos de trabalho, aceleramento no ritmo da produção e das ações somado ao desemprego estrutural, à implementação de novas tecnologias, com salários em declínio e/ou instáveis. Ressaltam-se ainda outras questões relacionadas à precarização dos contratos de trabalho, tanto aquelas denominadas de precariedade objetiva (contrato por prazo determinado, trabalho temporário) quanto as de precariedade subjetiva, tão ou mais prejudicial à saúde quanto a anterior, como a instabilidade dos contextos técnicos e organizacionais, em que se constata a fragilidade das organizações não governamentais e cooperativas que fazem os contratos com os profissionais terceirizados, e a responsabilização dos assalariados, tornando-os responsáveis pela sobrevivência das empresas. Constitui momento predominante da atual produção do capital a busca do envolvimento do trabalhador enquanto disposição intelectual-afetiva com a lógica da valorização do capital, portanto para além do "fazer" e do "saber" (Alves, 2005).

Todas essas condições de trabalho levam a uma verdadeira sobressolicitação mental, com uma sobrecarga informacional, um verdadeiro "soterramento" sob 
informações, hipersolicitação e tratamento paralelo de tarefas múltiplas, que provocam uma situação que poderíamos chamar de transbordamento cognitivo (Falzon, 2007). Como uma sensação de transbordamento e saturação, impressão de fazer o urgente passar na frente do importante, de não conseguir fazer o que se planificou, sem compreender o porquê, de permanente insatisfação com o trabalho realizado.

A reestruturação produtiva alterou substancialmente o perfil do trabalho e dos trabalhadores, assim como os determinantes da saúde-doença dos trabalhadores. Essas alterações modificaram também o perfil da morbi-mortalidade relacionada ao trabalho, assim como a organização e as práticas de saúde e trabalho (Dias, 1994).

A necessidade de transformações de práticas sociais para uma abordagem ampliada da saúde, para fazer frente aos crescentes índices de morbidade e mortalidade da população, ocorreu em um momento de efervescência do movimento da Reforma Sanitária e da democracia brasileira, e resultou na aprovação do Sistema Único de Saúde (1990) e na reorganização das competências das ações de segurança e saúde do trabalhador, na tentativa de superar a histórica fragmentação em três áreas: saúde, trabalho e previdência.

Em uma retrospectiva histórica situa-se o movimento de Reforma Sanitária iniciado no início da década de 1980, como marco da área e da denominação "saúde do trabalhador". A consolidação do conceito legal pela Lei n. 8.080, de 1990, do SUS - Sistema Único de Saúde, estabeleceu os procedimentos de orientação básicos como forma de instrumentalização das ações e dos serviços em saúde do trabalhador ${ }^{4}$.

Tradicionalmente, a atenção prestada aos trabalhadores se voltava para 0 trabalho formal. Porém em tempos de transformações constata-se que a precarização das relações de trabalho, mudou sem dúvida, a forma de compreender a questão, o que exigiu transformações radicais na maneira de se conceber e de se enfrentar os problemas daí decorrentes. A análise, sob uma perspectiva evolutiva e conceitual, indica que na medicina do trabalho o enfoque principal da determinação do processo de saúde/doença é individual, biologicista, como demonstra a sistematização realizada por Mendes e Oliveira (1995), no quadro a seguir.

4. Essa lei foi definida e ampliada em 1998 pela portaria n. 3.908, pela Norma Operacional em Saúde do Trabalhador - NOST-SUS. 
QUADRO 1 Situando o desenvolvimento conceitual em saúde do trabalhador

\begin{tabular}{|c|c|c|c|c|c|c|}
\hline $\begin{array}{c}\text { Determinantes } \\
\text { do Processo } \\
\text { Saúde/Doença }\end{array}$ & $\begin{array}{c}\text { Ação } \\
\text { Principal }\end{array}$ & $\begin{array}{c}\text { Caráter } \\
\text { Principal } \\
\text { da Ação }\end{array}$ & $\begin{array}{c}\text { Ator } \\
\text { Principal }\end{array}$ & Cenário & $\begin{array}{c}\text { Papel do } \\
\text { Usuário }\end{array}$ & $\begin{array}{c}\text { Campo da } \\
\text { Saúde }\end{array}$ \\
\hline 1. Biológico & $\begin{array}{c}\text { Tratamento } \\
\text { da doença }\end{array}$ & Técnico & Médico & Hospital & $\begin{array}{c}\text { O usuário é } \\
\text { o objeto }\end{array}$ & $\begin{array}{c}\text { Medicina } \\
\text { do Trabalho }\end{array}$ \\
\hline 2. Ambiental & $\begin{array}{c}\text { Prevenção } \\
\text { da doença }\end{array}$ & Técnico & Equipe & Ambulatório & $\begin{array}{c}\text { Usuário e } \\
\text { ambiente } \\
\text { são objetos }\end{array}$ & $\begin{array}{c}\text { Saúde } \\
\text { ocupacional }\end{array}$ \\
\hline 3. Social & $\begin{array}{c}\text { Promoção } \\
\text { da saúde }\end{array}$ & $\begin{array}{c}\text { Técnico/ } \\
\text { Político }\end{array}$ & Cidadão & Sociedade & Sujeito & $\begin{array}{c}\text { Saúde do } \\
\text { trabalhador }\end{array}$ \\
\hline
\end{tabular}

Fonte: Mendes e Oliveira, 1995.

A concepção atual de saúde do trabalhador entende o social como determinante das condições de saúde, sem negar que o adoecimento deve ser tratado e que é necessário prevenir novas doenças, privilegiando ações de promoção da saúde. Tal concepção entende que as múltiplas causas dos acidentes e das doenças do trabalho têm uma hierarquia entre si, não sendo neutras e iguais, havendo algumas causas que determinam outras (Mendes e Oliveira, 1995). Diferentemente das visões dicotomizadas anteriores, propugna-se que os programas de saúde incluam a proteção, a recuperação e a promoção da saúde do trabalhador de forma integrada, e que sejam dirigidos não só aos trabalhadores que sofrem, adoecem ou se acidentam, mas também ao conjunto deles (Dias, 1994). Essas ações devem ser redirecionadas para se alcançar as múltiplas mudanças que ocorrem nos processos de trabalho, sendo realizadas através de uma abordagem transdisciplinar e intersetorial e, ainda, com a imprescindível participação dos trabalhadores.

Entre os inúmeros desafios, aponta-se a necessidade de estruturação de uma abordagem que tenha como meta a realização de ações coletivas, no âmbito da vigilância, da promoção e da proteção da saúde nas quais o sujeito é parte essencial dessa ação.

Portanto, a área da saúde do trabalhador na contemporaneidade transcende os conhecimentos específicos da medicina do trabalho no sentido de compreender a relação capital-trabalho, na qual a saúde e o acidente de trabalho tornam-se expressão máxima das desigualdades geradas por esse conflito (Mendes, 2003). Torna-se fundamental, ao estudar a relação da saúde com o trabalho, entender como as so- 
ciedades constroem a saúde e quais são as possibilidades de sobrevivência individual e coletiva (Thébaud-Mony, 2000). O trabalho está, contudo - por meio de sua presença ou ausência - , totalmente ligado à evolução da questão da saúde, evidenciando a atualidade do nexo produção-reprodução da força de trabalho-consumo-ambiente-saúde-doença, vistos na sua integralidade (freire, 1995).

É importante reconhecer, ainda, na saúde do trabalhador, os desgastes físicos provocados pela modalidade do trabalho repetitivo, associado agora à característica polivalente da produção, e aos fatores psicossociais do desemprego crescente, pois fornecem as bases para a criação de estratégias ao trabalhador. Se o local de trabalho é o espaço no qual os processos organizativos estão disponibilizados para alcançar determinados fins, é importante perceber que os elementos que o integram não são homogêneos, pois os trabalhadores criam vínculos e regras próprias, e nem sempre obedecem ao dito, ao mensurável, ao controlável. A observação dessas práticas de trabalho, bem como das relações delas decorrentes, tornam-se pertinentes em estudos que buscam compreender a relação do adoecimento com o trabalho.

Destaca-se, portanto que a saúde do trabalhador pressupõe uma interface entre diferentes alternativas de intervenção que contemplem as várias formas de determinação do processo de saúde-doença dos trabalhadores (Mendes, 2003). É necessário pensar a saúde do trabalhador desde a sua organização na sociedade e no trabalho, compreendendo-se essa realidade sob uma perspectiva de sujeitos coletivos, conhecendo-os e reconhecendo-os historicamente. Desse modo, é preciso, além do diagnóstico e do tratamento, a implementação simultânea das modificações nos ambientes de trabalho, bem como o desenvolvimento de outras ações no âmbito da organização desses ambientes, que devem estar em consonância com as múltiplas mudanças nos processos de trabalho, as quais retratam a divergência de interesses entre capital e trabalho, quando emergem as doenças e os acidentes de trabalho.

Os avanços no campo político e teórico sobre a saúde do trabalhador não pode prescindir da construção de uma base legal e normativa que contemple diretrizes políticas para a atenção e a promoção da saúde do trabalhador. Destaca-se, assim, pela Portaria n. 1.679, de 19 de setembro de 2002, a criação da Rede Nacional de Atenção Integral à Saúde do Trabalhador (Renast), como estratégia para a elaboração desse instrumento, com ênfase nas ações assistenciais. Cabe ressaltar que essa portaria foi apoiada pelos profissionais e técnicos dos Centros de Referência em Saúde do Trabalhador - Cerest e setores do movimento dos trabalhadores, que reconheceram na iniciativa as possibilidades de institucionalização e fortalecimento da saúde do trabalhador, no SUS. Pela primeira vez seria possível contar com 
um financiamento extrateto das ações, vinculado à operacionalização de um Plano de Trabalho de Saúde do Trabalhador, em nível estadual e municipal. A partir de 2003, a coordenação da Área Técnica de Saúde do Trabalhador do Ministério da Saúde priorizou a implementação da Renast como a principal estratégia da Política Nacional de Saúde do Trabalhador (PNST) para o SUS (MS, 2004).

Essas ações são parte do debate em torno da articulação da área e da construção da proposta de Política Nacional de Segurança e Saúde do trabalhador — PNSST contendo importantes proposições e contemplando os papéis a ser desempenhado, entre outros, pelo Ministério da Saúde (assistência e vigilância), Ministério da Previdência (benefício por incapacidade e implementação do nexo epidemiológico presumido) e Ministério do Trabalho (diretrizes e normas de SST). Assim, a segurança e Saúde do Trabalhador - SST atende o intento de ampliação das ações de promoção, resultando na ampliação da cobertura dos trabalhadores, na harmonização de normas e articulação de ações; precedência da prevenção sobre a reparação; estruturação de uma rede integrada em SST; reestruturação da formação em SST; promoção de uma agenda integrada de estudos e investigação em SST (Lacaz, 2010). Porém, apesar desse esforço, não há ainda a efetivação da PNSST em decreto presidencial, para assim viabilizar efetivamente as ações propostas nelas contidas. Há de se considerar ainda divergências constantes na proposta da política, as quais representam questões de concepção travestidas, por vezes, de terminologias que, na sua essência, ocultam históricas tensões entre as áreas.

Ao demonstrar as implicações do trabalho sobre a saúde e os constantes embates que delineiam a área de saúde do trabalhador, identificam-se nas relações sociais da sociedade capitalista distintas perspectivas no campo ético, político e econômico. Tal constatação demanda sólido conhecimento teórico-metodológico e a articulação com as forças sociais, na defesa da saúde do trabalhador, como direito, e no sentido da emancipação do trabalhador, rompendo com abordagens conservadoras que concebe o adoecimento como fenômeno estranho ao processo de produção.

\section{Apontamentos sobre a dimensão teórico-metodológica do Serviço Social na saúde do trabalhador}

Tem-se na teoria social crítica a apropriação e a possibilidade da mediação da realidade que perpassa as duas categorias centrais e vitais, que são a saúde e o 
trabalho. Os embates teóricos que fundam o pensamento social frente ao capitalismo contemporâneo são dilemas que vêm desafiando a profissão, em simetria com a área da saúde do trabalhador. Ou seja, a mundialização da economia com sua crescente financeirização, o complexo de reestruturação produtiva, os embates em torno das políticas sociais e o papel do Estado são processos sociais em curso, que só podem ser compreendidos no campo teórico-metodológico, à luz do materialismo dialético-histórico.

O Serviço Social e a saúde do trabalhador referenciada na perspectiva da matriz marxista constituem "o fundamento para análise teórica da produção das condições materiais da vida social" (Netto, 2009, p. 682). Indissociavelmente, para entender a estrutura e a dinâmica da sociedade e determinações sobre o objeto saúde do trabalhador, há necessidade de um conhecimento dotado de força social e política para assim incidir sobre a realidade concreta circunscrita na saúde e no trabalho.

Portanto, ao evidenciar, o contexto social e político que envolve a saúde do trabalhador, é inegável o impacto de suas particularidades nos diferentes e crescentes espaços sócio-ocupacionais voltados para a atenção à esse aspecto. Trata-se, aqui, da necessidade de ampliar a busca pela compreensão das transformações sociais para ressignificar a realidade vivenciada pelos profissionais e pelos sujeitos vinculados à sua ação e, acima de tudo, para compreender como e onde se produz o processo de saúde-doença. Além disso é preciso, identificar quais as necessidades produzidas por ele e como se dá o processamento do trabalho nessa área. São questões que vêm demandando respostas, como já mencionado, no deciframento e na compreensão do contexto sócio-histórico, mas entendendo que a saúde do trabalhador envolve, necessariamente, outros quatro grandes pilares que representam e ampliam as mediações no campo ético-político, teórico-metodológico e técnico-operativo: a) a concepção de saúde; b) o processo de saúde-doença e seus determinantes sociais; c) a proteção social; d) a concepção de saúde do trabalhador. Assim, identificam-se categorias teóricas e também constitutivas da realidade com a qual o assistente social trabalha, fundamentalmente, por traduzir um conjunto de elementos que contribuem para o desocultamento e ao mesmo tempo para o enfrentamento do processo de saúde-doença por meio da identificação das necessidades de proteção social nele presentes e que são fundamentais para compreender o conceito de saúde do trabalhador.

Ao trazer inicialmente a base conceitual de categoria saúde objetiva-se explicitar que a noção ampliada de saúde caracteriza-se pela sua dimensão social, eco- 
nômica e política, ou seja, como aponta Thébaud-Mony e Appay (2000), a saúde é um processo dinâmico que se insere em diferentes lógicas, ou seja, representa por onde "o indivíduo se constrói e caminha, se inscreve no trabalho, nas condições de vida, nos acontecimentos, nas dores, no prazer, no sofrimento e em tudo o que constitui uma história singular, mas também a história coletiva".

Nessa perspectiva, a saúde é resultado das possibilidades de satisfação de necessidades básicas materializadas em direitos sociais, o que pressupõe a articulação das diferentes interfaces sociais entre modo de viver e acesso que os indivíduos têm aos bens e serviços, os quais contribuem para redefinir o binômio saúde/doença (Mendes, 2003). Entende-se, dessa maneira, que a saúde representa o acesso a um conjunto de condições básicas necessárias e um mecanismo de enfrentamento das desigualdades sociais. Reconhecidamente de forma materializada no plano legal, pelo conceito contemplado pela Lei n. 8080, que dispõe sobre o Sistema Único de Saúde no SUS (1990), a saúde é "resultante das condições de alimentação, educação, renda, meio ambiente, trabalho, transporte, emprego, lazer e liberdade, acesso à propriedade privada da terra e dos serviços de saúde" (Brasil, 1990).

Esse conceito representa não apenas um avanço legal, mas o reconhecimento do acúmulo produzido no campo do conhecimento que rompeu com conceituações construídas ao longo história social que vinculam saúde a causalidades unilaterais, conhecimento este incorporado pelo movimento da sociedade e de seus agentes políticos no bojo da Reforma Sanitária do Brasil em meados da década de 1980. Assim, os princípios que fundaram o Sistema Único de Saúde no Brasil, a partir da concepção ampliada de saúde, vão exigir políticas que atendam as diferentes necessidades em saúde. São princípios constituídos pela universalidade, integralidade e equidade e pela defesa da promoção à saúde, participação da população e dever do Estado. Sua efetivação requer políticas sociais e ações intersetoriais que contribuam para o enfrentamento do processo de saúde e doença.

As determinações sociais do processo de saúde-doença representam as condições sociais objetivas de vida e de trabalho da população. Reconhecem, assim, a saúde e a doença como um processo social, fundamentado na base material de sua produção e na articulação de processos biológicos e sociais. Isso ficou demonstrado pelos estudos de Laurell (1983), que explicita, fundamentalmente, a relação trabalho-saúde. Suas pesquisas mostram as mudanças do perfil epidemiológico através do tempo e evidenciam o caráter social no estudo comparativo, possibilitando ver que o adoecer/morrer são distintos nas diferentes classes sociais, demonstrando que as doenças são socialmente produzidas e historicamente determinadas. 
No que tange ao trabalho, destaca-se o lugar da organização social da produção, das expressões do trabalho hoje e as contradições presentes no desenvolvimento das forças produtivas que impactam sobre a saúde. Traduzem-se em processos de adoecimento e de exclusão do "mundo do trabalho", de perda do reconhecimento e identidade social do trabalhador, atingindo sua subjetividade e condicionando formas de ser e de viver.

A compreensão das multicausalidades e diferentes interfaces explicitadas a partir da concepção de saúde, do processo de saúde e doença na sua relação com o trabalho, constitutiva de determinações sociais, pressupõe reconhecê-las como demandas sociais a serem respondidas pelo Estado. Entretanto, o que a história recente tem demonstrado é que o atendimento dessas demandas depende da capacidade de poder dos diferentes agentes sociais e políticos transformarem suas necessidades em demandas políticas (Fleury, 1994), levando, assim, o Estado a dar respostas aos efeitos produzidos pela desigualdade social. Resposta constitutiva da formatação dos sistemas de proteção social que passa a representar, na perspectiva da análise explicitada na concepção de saúde, mecanismos de enfrentamento aos determinantes sociais que incidem no processo de saúde-doença e trabalho.

Entende-se, a partir desses apontamentos, que a proteção social representa a estruturação de um conjunto de políticas sociais que se efetivam pela intervenção do Estado visando à satisfação das necessidades sociais. Tais políticas resultam do reconhecimento das contradições existentes na sociedade capitalista e da concentração da riqueza coletivamente produzida. Esse reconhecimento é, historicamente, fruto da capacidade da classe trabalhadora de denunciar e de se rebelar contra formas de opressão e ausência de condições básicas para a sua reprodução. A proteção social é compreendida como "um conjunto de ações, institucionalizadas ou não, que visam proteger a sociedade ou parte desta dos impactos de riscos naturais e/ou sociais que incidem sobre o indivíduo e a coletividade, os quais decorrem fundamentalmente das desigualdades sociais que acompanham os diferentes estágios da sociedade capitalista" (Mendes, Wünsch e Couto, 2006).

A evolução dessa proteção social representa formas distintas de enfrentamento da questão social e responde inicialmente à organização do trabalho, avançando para o reconhecimento dos direitos inerentes à condição de cidadania (Fleury e Ouverney, 2008). Isso significa uma concepção de proteção social que engloba a noção de seguridade social (Pereira, 2000) e que vem superando a visão de seguro social que predominou nas primeiras legislações sociais. A seguridade social viabiliza-se por meio de políticas públicas que atendam, portanto, as mais diferentes 
situações de vulnerabilidade social que atingem os cidadãos, sejam elas decorrentes das relações sociais de produção, sejam consequência das contingências naturais dos ciclos vitais. A proteção social se afirma como mediações que concretizam direitos sociais, na inter-relação entre o político e o econômico na sociedade capitalista, uma vez que expressa a correlação de forças e embates políticos entre as classes sociais.

$\mathrm{Na}$ área da saúde do trabalhador, tem-se a proteção social como balizadora dos direitos a ele relacionados. Ela passa a ser definidora das reais e efetivas condições de garantia e preservação das condições de vida da classe trabalhadora. Também se constitui um indicador das insuficientes condições de reprodução social advindas do ofensivo movimento do capitalismo sobre o trabalho humano, ao longo de seu processo de acumulação.

No Brasil, a Seguridade Social contemplada constitucionalmente institui três grandes políticas sociais como constitutivas da proteção social: a Saúde, a Previdência Social e a Assistência Social. Isto representa avanços importantes, fundamentalmente no campo da política de saúde, pela sua universalidade e pelo reconhecimento da Assistência Social como política pública. Inaugura também uma nova relação entre Estado e a sociedade pelo seu caráter descentralizado e participativo. Entretanto, este modelo, enseja contradições históricas que não foram superadas, cujos reflexos incidem e se visibilizam na análise que se faz sobre o trabalho e a saúde do trabalhador. Factualmente o que se constata é que as refrações das expressões do trabalho presentes na saúde do trabalhador são respondidas pelo Estado de forma insuficiente.

A Previdência Social, que se constitui como núcleo central e histórico do sistema brasileiro de proteção social, não supera a clivagem entre capazes e incapazes para o trabalho, reforçando que é o trabalho que define quem tem ou não direitos (Boschetti, 2008). A natureza contratualista e securitária da Previdência reafirma, como bem destaca Fleury, "o caráter público do seguro social introduz uma contradição entre o vínculo individual e a garantia social do benefício" (1994, p. 154). O modelo de proteção social brasileiro estruturado através do trabalho assalariado produziu grandes lacunas ao longo de sua evolução, que se ampliaram a partir das necessidades que emergem das novas formas produtivas, as quais alteram não só a natureza dos processos de trabalho, mas, principalmente, o emprego formal e as relações de trabalho, constando-se assim um incontável número de trabalhadores desprotegidos socialmente. 
A fronteira entre proteção e desproteção social tensiona cotidianamente a saúde do trabalhador, particularizada no reconhecimento da relação trabalho e saúde. Tal fronteira situa-se na arena de conflitos do capital e trabalho, cujas manifestações principais estão relacionadas às condições em que o trabalho se realiza e à caracterização de doenças e acidentes relacionados ao trabalho. Ela repercute fundamentalmente no acesso ou não à renda legalmente instituída por meio "benefícios" pelo modelo de Previdência Social, seja pela ausência do reconhecimento do adoecimento seja, pela falta de vínculo com o sistema.

Aponta-se a Previdência Social como política social estratégica no campo da proteção social e dos direitos sociais, dado ao seu caráter distributivo de renda, sem, contudo, se dissociar das prerrogativas da política de saúde. Indica-se, também a lacuna presente entre Previdência e Assistência, na qual a segunda não consegue suprir as necessidades representadas pelo contexto do trabalho e de suas características amplamente já referidas.

A direção apontada sobre a proteção social e a saúde do trabalhador situa-se na elevação do papel do Estado numa perspectiva contra-hegemônica dos trabalhadores frente à imposição do capital sobre o Estado. Destaca-se que os avanços ocorridos nesse campo são produtos históricos, da permanente busca dos trabalhadores pelos seus direitos, mas atentos que estes, os direitos sociais, "não significam a superação da desigualdade e nem das formas de opressão vigente na vida cotidiana" (Behring e Santos, 2009 p. 280).

Reafirma-se, a partir das perspectivas apontadas, a definição de saúde do trabalhador como um processo dinâmico, social, político e econômico, que envolve diferentes manifestações de agravos relacionados aos processos de trabalho e aos processos sociais e que requer a articulação de um conjunto de conhecimentos e intervenções que possam incidir sobre as condições efetivas do processo de saúde-doença e de proteção social.

Essa formulação adquire sentido por meio da mediação teórico-metodológica, cuja perspectiva crítica conduz à identificação e à compreensão da construção social de invisibilização do processo de saúde-doença no trabalho. O cenário de desigualdade social, ao mesmo tempo em que produz esse processo, o oculta. A invisibilidade é resultante de aspectos objetivos e subjetivos nas relações sociais e que contribuem para tornar o fenômeno saúde-doença individualizado, descontextualizado e naturalizado. Os processos de adoecimento são ocultados frente à precarização das condições e relações de trabalho, o que vem levando ao não reconheci- 
mento dos agravos relacionados ao trabalho e à consequente ausência de proteção social (Wünsch, 2005).

Evidenciar a construção social da invisibilidade do processo de saúde-doença e compreendê-la significa tornar possível o desvendamento dos mecanismos sociais que ocultam esse processo e encontrar possibilidades de ação. Isso resulta, na perspectiva de superação do que vem limitando a área da saúde do trabalhador a incorporar os seus avanços e, ao mesmo tempo, possibilitar a construção crítica do conhecimento frente ao já instituído. Entendem-se os diferentes espaços sócio-ocupacionais em que a saúde do trabalhador se apresenta como objeto profissional para o assistente social, com imensos desafios. Porém a contribuição e as respostas da profissão não podem prescindir da busca e da elucidação da realidade social, bem como do reconhecimento, do lugar e do papel do trabalhador nesse contraditório campo de intervenção.

\section{Espaços sócio-ocupacionais e os desafios e respostas do Serviço Social para a área da saúde do trabalhador}

Os espaços sócio-ocupacionais que requerem a presença do assistente social na área da saúde do trabalhador representam o conjunto de serviços e programas que expressam a dinâmica das políticas sociais e da sociedade, bem como dos processos sociais que incidem nas antigas e novas demandas atendidas nesse campo. Esses espaços são expressões que conjugam, ao mesmo tempo, os avanços políticos da área e as refrações do trabalho sobre a saúde. Para o Serviço Social, o significado é de reconhecimento do papel e perfil profissional para com a área. Contudo, também se entende que as requisições desse trabalho confrontam-se com a condição de trabalhador assalariado, resultando numa tensa relação dessa condição com o projeto ético-político da profissão (Iamamoto, 2007). As contradições presentes nesses espaços dão a dimensão dos desafios para que sejam efetivados projetos que qualifiquem as ações profissionais na busca de respostas inovadoras que repercutam sobre as condições sociais e materiais da população trabalhadora.

O trabalho na área da saúde do trabalhador assume características interdisciplinares e intersetoriais, representado pela sua natureza multidimensional. O trabalho do assistente social é requisitado em diferentes instituições, na prestação direta de serviços e execução de programas, cujos principais espaços profissionais são: 
atenção básica de saúde, centros regionais de referência em saúde do trabalhador, hospitais públicos ou privados e serviços ambulatoriais referenciados, previdenciária social como espaço específico para o Serviço Social e reabilitação profissional, institutos próprios de previdência, serviços de medicina e segurança do trabalho vinculado a empresas e/ou instituições terceirizadas, gestão de recursos humanos para o desenvolvimento de programas voltados para a saúde do trabalhador, sindicatos que desenvolvem programas de promoção da saúde e defesa de direitos, serviços de vigilância e educação em saúde, trabalhos de assessoria e consultoria, organizações de ensino e pesquisa em saúde, entre outras áreas.

Entretanto, essa multiplicidade de espaços de intervenção precisa ser compreendida a partir da clareza dos limites representados pelos diferentes embates políticos e teóricos que refletem na implementação das políticas de saúde do trabalhador. Em outras palavras, como refere Raichelis (2010), os espaços profissionais condensam, e são confrontadas concepções, valores, intencionalidades, propostas de sujeitos individuais e coletivos, articulados em torno de distintos projetos em disputa no espaço institucional.

Nessa perspectiva, aponta-se outro dilema colocado para a profissão, que é o de identificar os nós górdios que vêm historicamente engessando as estruturas e determinando condutas profissionais e técnicas conservadoras e reprodutoras de antigas estratégias travestidas de novas. Transformam-se direitos sociais em "benefícios" estabelecendo uma tênue relação entre a garantia e/ou assistencialização desse direito. ${ }^{5}$

Pensar a intervenção na área da saúde do trabalhador e os diferentes condicionamentos sobre o processo de trabalho em que se insere o assistente social requer, portanto, um conjunto de competências e exigências. Assim, alguns elementos constituem-se como eixos norteadores para o trabalho. Inicialmente, aponta-se o

5. Deve-se registrar, que históricos espaços profissionais nas políticas voltadas para a saúde do trabalhador de natureza pública, como na Previdência Social, e/ou de caráter privado, a exemplo do Serviço Social da Indústria - SESI, representaram os primórdios da profissão na área. Entretanto, esses também são produtos históricos de práticas que oscilam entre o conservadorismo e a busca de rupturas que acompanham o processo de renovação da profissão nas décadas de 1970 e 1980. Ao mesmo tempo, destaca-se que ocorreu um esvaziamento desses espaços na década de 1990, em especial na Previdência Social, recuperados recentemente após ampla mobilização da categoria, que resultou no ingresso de um contingente significativo de profissionais e que se encontram no momento em franco embate com o racionalismo e o conservadorismo institucional frente à necessidade de implementação de projetos político-institucionais e intersetoriais na área da saúde do trabalhador. 
caráter interdisciplinar do trabalho, demarcando um lugar que conjuga os diferentes conhecimentos e as especificidades das profissões ali inseridas, conferindo uma dimensão processual ao trabalho para superar a fragmentação do saber e das limitações encontradas durante o processo de intervenção e de conhecimento.

A compreensão das diferentes dimensões que envolvem os processos de saúde-doença e trabalho potencializa e amplia o próprio espaço profissional no enfretamento das suas determinações. Para tanto, nessa perspectiva, o trabalho do assistente social se materializa na capacidade de trabalhar em equipes com formação interdisciplinar, buscando a intersetorialidade e a interface da saúde do trabalhador com as demais políticas sociais. Esse trabalho exige uma abordagem interinstitucional, de reconhecimento das diferentes instituições e programas que estão relacionados a esse campo, em particular os vinculados à Seguridade Social, contribuindo assim para a integralidade das ações e de universalidade no acesso aos serviços em todos os níveis de proteção social.

Significa, assim, situar o objeto de trabalho do assistente social na saúde do trabalhador no processo de saúde-doença e suas expressões decorrentes do trabalho e diretamente atreladas ao processo de produção e reprodução social que incidem na vida do trabalhador. Para tal, pressupõe dos profissionais o conhecimento teórico-metodológico e requer uma intencionalidade crítica, clareza ética, que se expressa no compromisso político com a transformação e a superação do seu objeto. Portanto, requer um conjunto de competências, as quais perpassam a compreensão das relações que envolvem o processo de saúde-doença e trabalho; das múltiplas vivências dos sujeitos e de como percebem o processo de adoecimento; do conhecimento das políticas sociais e dos princípios que as norteiam; da capacidade de leitura crítica da realidade, de análise socioinstitucional e de articulação com a rede de serviços; da capacidade de desvendamento da questão social dando visibilidade à mesma a partir da apreensão das suas expressões no processo de saúde-doença e trabalho, na demanda institucional, na vida dos sujeitos e nos impactos desse processo na família e no meio social; da postura investigativa, interpretativa, crítica, ética, de escuta, reflexiva, relacional, propositiva, da capacidade de mobilizar pessoas, profissionais e instituições; da capacidade de trabalhar interdisciplinarmente no planejamento, na gestão, na execução e na implementação de políticas e na avaliação delas; da capacidade de avaliação do impacto e da efetividade do trabalho profissional com vistas a incidir de forma qualitativa no objeto de intervenção; da sistematização e reflexão acerca do processo de trabalho e disseminação do conhecimento a partir dele. 
Reitera-se que as competências evidenciadas são construídas a partir de um referencial teórico crítico que articula as diferentes dimensões do processo de trabalho na área, mas que deve se aliar à capacidade de esses profissionais estabelecerem mecanismos de formação permanente, - o que implica um aprendizado sistemático que valorize a experiência profissional e a reflexão sobre a mesma, resultando em novas estratégias de intervenção, vislumbrando novos "sentidos" para o trabalho e ao mesmo tempo ampliando o significado social da profissão.

\section{Considerações finais}

Os desafios colocados para o assistente social na área da saúde do trabalhador representam dilemas compartilhados e debatidos pelo conjunto da categoria. Neles estão presentes questões que remetem ao constante embate entre projetos políticos e ético-políticos da profissão.

Nessa área do conhecimento e intervenção, o assistente social é requisitado a responder a demandas legitimadas pelas contradições produzidas na ofensiva do capital sobre os trabalhadores. O trabalhador Assistente Social não fica imune às confrontações advindas desse contexto. Sobre ele impactam também as mesmas exigências colocadas sobre o trabalho e os agravos sobre a sua saúde do conjunto dos trabalhadores. Conjugam-se a essa realidade as condições objetivas para exercer o trabalho, os limites colocados pelos órgãos empregadores, pelas relações de poder, pelo estatuto político-legal e recursos programáticos e financeiros, entre outras determinantes que interferem nas atribuições profissionais. A concretude do trabalho profissional oscila entre o reconhecimento do trabalhador, o impacto de suas ações sobre a saúde e o trabalho e os limites resultantes de múltiplas determinações sobre o processo de trabalho em que se insere o assistente social.

As diferentes formas de precarização do trabalho e o crescimento dos acidentes e adoecimento resultantes do trabalho e as necessidades, daí resultantes, são marcas históricas que sinalizam para a sociedade o lugar desse fenômeno, como produto das relações sociais da sociedade capitalista. Ao Serviço Social compete realizar o enfrentamento das diferentes formas e dimensões de como se dá à produção e reprodução das relações sociais. Assim, deve a profissão, como bem aponta Iamamoto (2007), contribuir para a progressiva democratização dessas relações.

A saúde do trabalhador choca-se com a lógica do capital, onde estão representados distintos interesses de classe e na dimensão dos acidentes e das doenças 
resultantes do trabalho ocorre a ampliação e a visibilidade que marcam essas contradições existentes. Por isso a necessária ruptura com perspectivas conservadoras, neoconservadoras e moralizadoras presentes na área, as quais vêm se constituindo em obstáculos, principalmente, para a promoção de políticas voltadas para a saúde do trabalhador, que representem a defesa da saúde enquanto direito.

Portanto, as mediações políticas, teóricas e metodológicas processadas pelo assistente social na sua imersão na área da saúde do trabalhador expressam amplas possibilidades, as quais devem ser construídas a partir da participação das forças políticas, de estabelecer mecanismos que superem a fragmentação das políticas específicas e transversais da saúde do trabalhador, reconhecimento e elevação do papel do Estado, na ampla necessidade de compreender que só há efetivo desenvolvimento social à luz do reconhecimento da defesa do trabalho e da saúde.

Os desafios apontados na interface entre Serviço Social e saúde do trabalhador, devem orientar novas problematizações para a área, contribuir para o avanço do conhecimento e, acima de tudo, enfrentar o que se identificou aqui como uma dispersa demanda. Essa demanda é constitutiva da direção ético-política da profissão e das exigências impostas pela realidade social.

Nessa perspectiva é que se assinala a necessidade imperiosa da plena apropriação de referenciais teóricos e metodológicos como definidores do trabalho profissional e da contribuição para área da saúde do trabalhador. Para tanto é imprescindível sua incorporação na agenda política da categoria em articulação com outras forças políticas comprometidas com a saúde do trabalhador. É preciso pensar na saúde do trabalhador para além de condição necessária à reprodução social da classe trabalhadora, mas como um direito social inerente ao homem, condição indispensável para a vida e a sociabilidade humana.

Recebido em 8/4/2011 - Aprovado em 13/6/2011

\section{Referências bibliográficas}

ALVES, G. O novo (e precário) mundo do trabalho: reestruturação produtiva e crise do sindicalismo. 1. reimp. São Paulo: Boitempo, 2005.

ANTUNES, R. Os sentidos do trabalho: ensaio sobre a afirmação e negação do trabalho. São Paulo: Boitempo, 1999. 
ANTUNES, R. O caracol e a sua concha: ensaios sobre a nova morfologia do trabalho. São Paulo: Boitempo, 2005.

AUGUSTO, E. Premissas para um novo sindicato. In: GOMES, Álvaro (Org.). O trabalho no século XXI: considerações para o futuro do trabalho. São Paulo: A. Garibaldi; Bahia: Sindicato dos Bancários da Bahia, 2001.

BRASIL. Ministério da Saúde. Lei n. 8080 de 19 de setembro de 1990: Dispõe sobre o Sistema Único de Saúde. Disponível em: <http://www.saude.gov.br>. Acesso em: 12 mar. 2011.

. Portaria n. 3.908, pela Norma Operacional em Saúde do Trabalhador - NOST-SUS. Disponível em: <http://www.saude.gov.br>. Acesso em: 12 mar. 2011.

Portaria n. 1.679 de 19 de setembro de 2002. Rede Nacional de Atenção Integral à Saúde do Trabalhador (Renast). Disponível em: $<$ http://www.saude.gov.br $>$. Acesso em: 12 mar. 2011.

. Portaria Interministerial MPS, MS e MPE n. 800 de 3 de maio de 2005. Disponível em: <http://www.saude.gov.br>. Acesso em: 12 mar. 2011.

BEHRING, E.; SANTOS, S. Questão social e direitos. In: Serviço Social: direitos sociais e competências profissionais. Brasília: Cfess/Abepss, 2009.

BOSCHETTI, Ivanete. Seguridade Social e trabalho: paradoxos na construção das Políticas de Previdência e Assistência Social no Brasil. Brasília: Letras Livres e Editora da UnB, 2008.

Política Nacional de Saúde do trabalhador, proposta para consulta popular, janeiro de 2004. Disponível em: <http://www.saude.gov.br>. Acesso em: mar. 2011.

DIAS, E. C. Aspectos atuais da saúde do trabalhador no Brasil. In: ROCHA, L. E.; RIGOTTO, R. M.; BUSCHINELLI, J. T. (Orgs.). Isto é trabalho de gente? Vida, doença e trabalho no Brasil. Petrópolis: Vozes, 1994.

FALZON, P (Org.). Ergonomia. São Paulo: Blücher, 2007

FLEURY, Sônia. Estado sem cidadãos. Rio de Janeiro: Fiocruz, 1994.

FLEURY, S; OUVERNEY A. M. Política de saúde: uma política social. In: GIOVANELLA, L. et al. (Orgs.). Politicas e sistema de saúde no Brasil. Rio de Janeiro: Fiocruz; 2008. p. 23-64.

FREIRE, Lúcia. Serviço Social na reestruturação produtiva. São Paulo: Cortez, 1995.

IAMAMOTO, Marilda V. O Serviço Social em tempo de capital fetiche: capital financeiro, trabalho e questão social. São Paulo: Cortez, 2007. 
LACAZ, Francisco Antonio de Castro. Politica Nacional de súde do trabalhador: desafios e dificuldades. In: SANTANA, Raquel Santos et al. (Org.). Avesso do trabalho II: trabalho, precarização e saúde do trabalhador. 1. ed. São Paulo: Expressão Popular, 2010.

LAURELL, A. C. A saúde-doença como processo social. In: NUNES, E. D. (Org.). Medicina social: aspectos históricos e teóricos. São Paulo: Global, 1983.

; NORIEGA, M. Processo de produção e saúde trabalho: e desgaste operário. São Paulo: Hucitec, 1989.

LESSA, S. Trabalho e proletariado no capitalismo contemporâneo. São Paulo: Cortez, 2007.

MARTINELI, Maria Lúcia. O uso de abordagens qualitativas na pesquisa em Serviço Social: um instigante desafio. São Paulo: NEPI, 1994. (Caderno do Núcleo de Estudos e Pesquisa sobre Identidade, n. 1).

; OLIVEIRA, P. A. B. Medicina do trabalho: o desafio da integralidade na atenção à saúde. In: VIEIRA, S. I. V. (Coord.). Medicina básica do trabalho. Curitiba: Gênesis, 1995. v. 4.

; WÜNSCH, D.; COUTO, B. Verbete proteção social. In: CATTANI, A. D.; HOLZMANN, L. Dicionário de trabalho e tecnologia. Porto Alegre: UFRGS, 2006. p. 212-215.

WÜNSCH, Dolores Sanches. Formação em saúde do trabalhador. In: ENCONTRO NACIONAL DE PESQUISADORES EM SERVIÇO SOCIAL (ENPESS), 11., Anais eletrônicos. São Luís: Abepss, 2008.

MENDES, J. M. R.; CASTILHOS, R. Texto Conferência Serviço Social na Saúde. 2008.

NETTO, J. P. Introdução ao método na teoria Social. In: Serviço Social: direitos sociais e competências profissionais. Brasília: CFESS/Abepss, 2009.

PEREIRA, Potyara A. P. Necessidades humanas: subsídios à crítica dos mínimos sociais. São Paulo: Cortez, 2000.

RAICHELIS, Raquel. Intervenção profissional do assistente social e as condições de trabalho no Suas. Serviço Social \& Sociedade [online]. 2010, n. 104, p. 750-772. Disponível em: $<$ www.scielo.br/pdf/sssoc/n104/10.pdf>. Acesso em: 20 mar. 2011

THÉBÁUD-MONY, Annie; APPAY, B. Précarisation sociale. Paris: Institut de Recherche sur les Sociétes Contemporaines, 2000. Mimeo.

WÜNSCH, Dolores Sanches. A construção da desproteção social no contexto histórico-contemporâneo do trabalhador exposto ao amianto. Tese (Doutorado em Serviço Social) Faculdade de Serviço Social, PUC-RS, Porto Alegre, 2005. 